\title{
Quality Culture Adaptation Criteria for Construction Organization
}

\author{
Jacqueline Wena Dhelbi, Faridah Ismail, \\ Norfashiha Hashim, Norsyakilah Romeli \\ Faculty of Architecture, Planning and Surveying, \\ UniversitiTeknologi Mara (UiTM), 40450 Shah Alam, Selangor, Malaysia
}

jacqueline_wena@yahoo.com, hjhidah@yahoo.co.uk, kilaromeli@gmail.com

\begin{abstract}
The construction sector has lagged behind regarding quality development. Though quality issues have become the major concern in the construction industry, there is an absence of the theory that propagates construction quality which lead to quality performance. This paper discusses the adaptation criteria for the Malaysian contractors that could be adapt for the management as well as the staff. Extensive literature reviews were done to identify adaptation criteria within the Malaysian context. Therefore, this paper encourages the contractors to implement these criteria in the workplace to improve the quality of life of contractors that will lead to project success.
\end{abstract}

Keywords: Quality Culture; Adaptation; Criteria; Malaysian

eISSN 2398-4279 @ 2018. The Authors. Published for AMER ABRA cE-Bs by e-International Publishing House, Ltd., UK. This is an open access article under the CC BY-NC-ND license (http://creativecommons.org/licenses/by$n c-n d / 4.0 /$ ). Peer-review under responsibility of AMER (Association of Malaysian Environment-Behaviour Researchers), ABRA (Association of Behavioural Researchers on Asians) and CE-Bs (Centre for EnvironmentBehaviour Studies), Faculty of Architecture, Planning \& Surveying, Universiti Teknologi MARA, Malaysia.

https://doi.org/10.21834/ajqol.v3i14.179 


\subsection{Introduction}

Many criticisms have been pointed to the construction industry especially for its workmanship performance, construction processes, the organizations involved, the materials, etc. These elements were under great pressure for better quality culture in construction. 9th Malaysian plan design and build projects reported $91 \%$ faced quality problems while conventional projects faced $84 \%$ (JKR Report, 2011). Besides, the current management practice such as the ISO shows only $13.57 \%$. Certified G7 contractors registered with CIDB. The long list of project failures goes on continuously and to avoid this there is a need to improve and upgrade the standard, quality and professionalism in all discipline.

The nature of the industry which is poor quality of project deliverables is one of the most critical problems in the construction industry (Mahmood, 2006). Many completed projects were reported costs much higher than the actual contract sum due to poor quality. In Malaysia, the construction sector contributes significantly to the economic growth for improving the quality of life. The construction sector has been playing a significant role in aggregate economy of the country in term of its contribution to revenue generation which encourages the gross domestic product and the socio-economic development of Malaysia. In addition, it is in line towards economic transformation program, construction industry transformation program (CITP) 2016-2020; to improve the overall quality, safety and professionalism of the industry as well as Public Service Delivery which is to focus on Rakyat Quality of Life.

However, the construction firms are continually struggling with quality issues (Mahmood 2006) as many studies shown that many organizations failed to perform quality that the continuous improvement cannot be maintained leads to unachieved goals (Schroeder et al., 2010). In spite of the studies mentioned above, there is no review on quality and adaptation criteria to be considered for contractors. In Malaysia construction environment, studies shown that the main quality issues are the involvement of the contractors in the construction process and implementation of a formal quality system.

The current state of Malaysian construction industry reported in the media and regarded as synonymous with construction players evidence that the construction industry to with ethical issues. Issues such as wasted tender expenses, tendering uncertainty, increased project costs, economic damage, blackmail, criminal prosecutions, fines, blacklisting and reputational risk is the unwanted unethical behaviour by the construction industry parties that may impact the quality of projects as well as the construction and engineering companies (Rahman, et al., 2007).

The topic quality culture has become one of the vital subjects of the study recently, and numerous publications have been produced in the academic journal. However, studies have shown that not many organisations can reach their goals. Therefore, this paper reviews recent paper and book on the topic. In this study, the adaptation criteria that need to be considered by the contractors or construction players for the quality of life of the contractors in the workplace are reviewed. The author believes that quality of life will only improve if the construction players willing to adapt and consider to make a new improvement for the sake of the construction industry performance. The adaptation criteria studied in this paper are necessary and proven to create a quality culture in the construction industry. Therefore, this 
study aims to identify the criteria that need to be considered by the contractors or construction players for the quality of life of the contractors in the workplace.

To address this shortcoming, this study adopts a new approach to study quality culture in the construction industry. The Quality Adaptation Model developed by Pawlowski (2007) provides a model on how to use and adapt the quality standard for the learning, education and training industry. This model is adapted and used to suits the construction industry to analyse the adaptation criteria towards quality culture for Malaysian contractors.

\subsection{Literature Review}

Quality culture is a significant factor in successful implementation of quality and it is defined as all levels of employees are truly committed to quality in their works that strive for zero defects and excellence in the things they do (Adnan, 2012). However, difficulties in maintaining a quality culture in construction organisations are believed caused by many obstacles that blocking them from achieving the quality standards. The obstacles lack of management commitment and understanding of quality, lack of awareness, inadequate knowledge, lack of clarity of the guideline, lack of understanding about the benefits of continuous improvement and worst is ignoring the importance of customers (Seetharaman. et. al, 2006).

The construction industry involves substantial capital investments, providing large-scale opportunities for rent extraction as well as investments that usually cannot be redeployed after implementation. Unethical practices can take place in every phase of a construction project during planning and design, pre-qualification and tender, project execution and operation and maintenance. Such practices can result in projects which when completed are considered unnecessary, unsuitable, overlay complex components, overpriced or delayed. These problems occurred because of the lack of strong support from the management and also the lack of effective communication (Hamzah et al., 2008). To eliminate the unhealthy behaviour, the need to add in the quality culture in the industry must support by promoting the need for adaptation to a better quality management system.

The inability to complete projects on estimated time has been a trend, and Malaysian construction industry has been point as underachieving by CIDB, and the industry must have a need of adaptation urgently by transforming the construction practices, technology, work practices and processes as well as mentality in order to sustain continuous improvement by referring to efficient benchmarking and performance measurements (Riazi et al., 2011). There are six factors affecting the quality which is the design, labours, materials, equipment, quality systems, site staff, owners and contractors (Ahmed, 2016).

Adaptation issues where the construction parties resistant to change and have the lack of sense of urgency in implementing the quality management practices in the workplace still occur even though the quality management practices has been extended to the organisations (Yamada et. al, 2013). The benefit that contractor might gain by understanding the adaptation criteria is to experiencing continuous improvement of processes, people and system, the reward system, team work, the measurement of performance and communication since all these are the critical success factors in the organization as continuous improvement of 
processes, people and system, the reward system, team work, the measurement of performance and communication are all critical success factors for the sustainable quality management system (Kaziliunas, A. ,2010).

On the other hand, not every actor implement quality (Hoonakker, 2010). The relationship between culture and quality adaptation are still critical, and it has not been adequately studied (Schroeder, 2010). According to Keng (2011) companies still, prefer the traditional method of quality management practices such as experiments and inspection that obviously shows they are afraid of making the change. Lack of management commitment also still becomes the major factor that leads to quality problems (Said et al., 2009). Therefore, quality culture in construction organisation must be created (Janipha, 2013). Hamzah (2011) supported that Malaysian quality culture need to be strengthened as the quality of life will only exist if the parties follow or adopt all the criteria of quality culture. The adaptation criteria are necessary to create a quality culture in the construction industry.

\subsection{Definition of Terms}

Culture itself is defined as the pattern of arrangement, material or behaviour which has been adopted by society as the accepted way of solving problems (Mahmood, 2006) which include existing habits and the understood beliefs, norms and values which emphasise and rule behaviour (Ahmed, 1999).

Quality Culture has many definitions by many scholars/different views and perspectives. Wahab (2006) stated that quality culture is an organisational value system that results in an environment that is conducive to the establishment and continual improvement of quality. Gryna (2007) described quality culture as the pattern of habits, beliefs and behaviour concerning quality and Linkow (1989) define quality culture as an organisation having clear values and beliefs that foster total quality behaviour.

\subsection{Elements of Quality Culture}

Mahmood (2008) had discovered thirteen (13) elements of quality culture in the context of Malaysian construction industry whereby Delgado (2008) stated that they are nine elements of Quality culture. The elements are a) Leadership \& top management; b) Customer focus; c) Continuous improvement; d) Education \& training; e) Teamwork; f) Worker involvement; g) Empowerment; h) Supplier partnership; i) Rewards and recognition j) Communication; k) Motivation; I) Organization structure; m) Strategic \& quality policy.

\subsection{Adaptation Criteria}

Longman Dictionary states that adaptation means to gradually change behaviour and attitudes to be successful in a new situation. Adaptation helps the organisation to develop quality systems and to improve the quality of their processes, products and services (Pawlowski, 2008). Cultural adaptation happens when firms extend their operations into new institutional contexts they are highly likely to adapt their existing structures and cultures. Cultural adaptation has been studied from an individual level, but little has been written at the organisational level. Francis (1991) defines cultural adaptation as "An attempt to elicit approval from members of a foreign culture by seeking to become behaviourally more similar 
to members of that culture. Whereby, Schein (1992) define adaptation as "The focus on behaviour rather than values or assumptions, and the aim of eliciting acceptance, suggests that cultural adaptation takes place at the 'behavioural' level of the behaviour, values/beliefs, underlying assumptions (Jia, 2016). Pawlowski (2008) states that there are 13 criteria of quality adaptation. These criteria can be grouped into four main components. The first one is context setting.

Table 1:Adaptation process and criteria

\begin{tabular}{lll}
\hline Phase & & \multicolumn{1}{c}{ Criteria } \\
\hline Context setting & 1. & Vision development \\
& 2. & $\begin{array}{l}\text { Policy \& strategy development } \\
\text { 3. }\end{array}$ \\
& & \\
Model Adaptation & 4. & \\
& 5. & Sentification of actors \\
& 6. & Selection of methods \& instruments \\
& 7. & Selection of Metrics \& indicators
\end{tabular}

\begin{tabular}{|c|c|c|}
\hline $\begin{array}{l}\text { Implementation and } \\
\text { Adoption }\end{array}$ & $\begin{array}{l}8 . \\
9 . \\
10 .\end{array}$ & $\begin{array}{l}\text { Implementation } \\
\text { Participation } \\
\text { Adoption \& Usage }\end{array}$ \\
\hline Quality Development & $\begin{array}{l}11 . \\
12 . \\
13 .\end{array}$ & $\begin{array}{l}\text { Evaluation } \\
\text { Continuous development } \\
\text { Improving quality discourse }\end{array}$ \\
\hline
\end{tabular}

(Source: Pawlowski, 2008)

\subsubsection{Context setting}

In this phase, statements should be produced by an organisation where their long terms objectives which contained vision strategy and policy are well documented for further revision and improvement. In another word, the organisation must provide a basis for quality development for every party use. Pawlowski added that this stage shall not be under the management responsibility solely but to all the staffs in the organisation and should be a part of everyday operations. The main reason for context setting is to provide the basis for quality development. Context setting covers all preparatory activities for the adaptation process.

\subsubsection{Model Adaptation}

In this stage, the organisation must identify all the relevant actors and relevant process or job description to produce a comprehensive process for the ongoing project by using guidelines such as ISO or TQM and other Quality Management System that the company adopt. Each task is assured to have their quality objectives to have better outcomes. Besides that, this stage also covered to choose the right machinery or tools to be adopted for the organisation 
daily use. For example, by using new types of construction rather than the traditional way. Model adaptation is where models or guidelines are used to establish details of quality development in the organisation. It is where actors from every department are identified and involved in the process.

\subsubsection{Implementation and Adoption}

This is where the organisation was making the concepts work which they have developed a strategy to achieve the quality culture. Hoonakker (2010) added that contractor could gain various benefit such as reduced rework, improved schedule performance, improved relationships with other construction player and there will be more customers would want to repeat services due to higher customer satisfaction if they do quality improvement.

\subsubsection{Quality Development}

Finally, is the stage of improving the organisation's performance. This stage requires quality system to be continuously evaluated, updated and improved to be aligned to the organisation objectives. For example, the quality system has to be reviewed twice a year to ensure its effectiveness to the company. Additionally, the adequacy of the methods, instruments or tools must also be evaluated for improvement action to be taken. A broad awareness and discussion on the importance of quality take place at this stage.

\subsection{Methodology}

Since the purpose of this paper is to identify the adaptation criteria towards quality culture, a review of the literature is conducted to study and present the factors and the issues related to the research. The author examines the literature review by reviewing materials in related with the topic such as books, proceeding paper, journal and official webpage. The literature was reviewed using content analysis techniques and general review. From the literature review, the issues of adaptation and quality culture were outlined and the information was obtained.

\subsection{Results and Discussion}

As the theme is regarding on $\mathrm{QOL}$ and Adaptation criteria towards quality culture, the authors review academic and proceeding journal, webpage and also book section. Related wording to the topic of quality of life, Adaptation Criteria, Quality culture, Contractors and Malaysian Construction industry are searched. Somehow, there are publications that might have been overlooked by the authors during the study.

\subsection{No existing adaptation criteria for Construction Industry}

There is no framework on quality adaptation for the construction industry context. It was also found that existing models not focused on the actors responsible for the task identified. In reviewing this study, the author discusses not only on the criteria but also the definition of quality culture as well as the elements of the quality culture. It was found out that there are 
fewer studies on quality culture done by other researchers.

\subsection{Actors Responsible for Adapting Quality Culture}

From the discussions, we found that actors play important roles in ensuring the continuous improvement of a project. The top management is the main actors in the construction industry where they should provide direction and gives a commitment to their employees. The vision of the leader will guide their employees in reaching their project goals and objectives. Although the manager is the leader in the organisation, quality is everyone's responsibility as everyone must play their part by understanding the importance of quality and changing their behaviour towards the elements of quality culture.

\subsection{Nature of the Industry}

The nature of the industry itself which is the poor quality of project deliverables because the construction industry is project-based and it requires specifics processes which are complex as well as integrating many different specialists from different background. This caused the solution to every problems arisen may have different solutions as ideas come from a various source. The drivers for each party in the industry may also differ from one another as clients priority is to have the end product to be completed on time with low budget whereas, contractors want profits. To save cost, top management not willing to take the risk to try any new systems and most likely stick with the same method while most contractors might appoint unskilled workers that eventually produced low-quality products and services.

\subsection{Conclusion}

This paper used the Quality Adaptation Model developed by Pawlowski (2008) to examine the adaptation criteria towards quality culture for the Malaysian contractors. The evidence showed that construction industry had faced many problems in getting good results of quality performance due to the complicated nature of the industry. Even though there are many quality management systems are promoted to help the industry to improve the quality issues, the main barriers are the behaviour of the player itself who are not willing to take the risk and make changes to the existing practices. Somehow, some companies managed to implemented quality but just for the sake to fulfil the standard quality obligations and requirements. The results of this paper make two important contributions. Firstly, the adaptation criteria were analysed from learning, education and training industry which is similar to the needs of the contractor's organisation. Further research on construction industry adaptation criteria may benefit the organisation from the adaptation models. Secondly, the actors responsible for the success of quality culture were observed and they are the top management and the employees engaged with the organisation. This is because quality are everyone's responsible and no one should look down on the importance of quality. Therefore, a need of cultural adaptation in the current culture should be done to contribute to successful implementation of quality management. Furthermore, contractors may refer to these adaptation criteria in their daily projects as the adaptation criteria will promote better quality of life. 


\section{Acknowledgement}

Authors gratefully acknowledge and are grateful for the financial support of the Geran Inisiatif Penyelidikan (GIP) by Universiti Teknologi MARA for this research. Special thanks also go to the reviewers for their invaluable comments on this paper.

\section{References}

Adnan, H., Hashim, N., Mohd, N., Yusuwan, \& Ahmad, N. (2012). Ethical Issues in the Construction Industry: Contractor's Perspective. Procedia - Social and Behavioural Sciences, 35(December 2011), 719-727. http://doi.org/10.1016/j.sbspro.2012.02.142

Ahmed, P. K., Loh, Y. E. \& Khairi, M. (1999). Cultures for continuous improvement and learning, Total Quality Management, Vol. 10, No.4\&5, pp. 426-434.

Ali, N. M., Jangga, R., Ismail, M., Kamal, S. N.-I. M., \& Ali, M. N. (2015). Influence of Leadership Styles in Creating Quality Work Culture. Procedia Economics and Finance, 31(15), 161-169. http://doi.org/10.1016/S22125671(15)01143-0

Barrett, P. (2000). Systems and relationships for construction quality. International Journal of Quality \& Reliability Management, 17(4/5), $377-392$.

Delgado-hernandez, D. J., \& Ã, E. A. (2008). A framework for building quality into construction projects - Part I, 19(10), 1013-1028. http://doi.org/10.1080/14783360802264061

Heravitorbati, A., Coffey, V., \& Trigunarsyah, B. (2011). Assessment of Requirements for Establishment of a Framework to Enhance Implementation of Quality Practices in Building Projects. International Journal of Innovation, Management and Technology, 2(6), 465. http://doi.org/http://dx.doi.org/10.7763/IJIMT.2011.V2.177

Hoonakker, P., Carayon, P., \& Loushine, T. (2010). Barriers and benefits of quality management in the construction industry: An empirical study. Total Quality Management \& Business Excellence, 21(9), 953-969. http://doi.org/10.1080/14783363.2010.487673

Janipha, N. A. I., \& Ismail, F. (2013). Conceptualisation of Quality Issues in Malaysian Construction Environment. Procedia - Social and Behavioural Sciences, 101, 53-61. http://doi.org/10.1016/j.sbspro.2013.07.178

Jia, F., Rutherford, C., \& Lamming, R. (2016). Cultural adaptation and socialisation between Western buyers and Chinese suppliers : The formation of a hybrid culture, 25, 1246-1261.

Kaziliunas, A. (2010). Success Factors for Quality Management Systems : Intelectual Economics, 2(8), 30-38.

Khan, R. A., Liew, M. S., \& Ghazali, Z. Bin. (2014). Malaysian Construction Sector and Malaysia Vision 2020: Developed Nation Status. Procedia - Social and Behavioural Sciences, 109, 507-513. http://doi.org/10.1016/j.sbspro.2013.12.498

LinkLow, P. (1989). Is your culture ready for total quality?. Quality Progress

Mahmood, W. Y. W., \& Mohammed, A. H. (2008a). Towards a quality culture in Malaysian construction industry. In: Quality Management System in Malaysian Construction Industry, 93-117. Retrieved from 
http://www.penerbit.utm.my/bookchapterdoc/FKSG/bookchapter_fkkksa08.pdf

Mahmood, W. Y. W., \& Mohammed, A. H. (2008b). Towards a quality culture in Malaysian construction industry. In: Quality Management System in Malaysian Construction Industry, 93-117. Retrieved from http://www.penerbit.utm.my/bookchapterdoc/FKSG/bookchapter_fkkksa08.pdf

Matei, A., \& Antonie, C. (2015). The Need for Positive Change: Adapting Management in Public Administration. Procedia Economics and Finance, 26(15), 345-350.

Pawlowski, J. M. (2007). The Quality Adaptation Model : Adaptation and Adoption of the Quality Standard ISO / IEC 19796-1 for Learning, Education, and Training, 10, 3-16.

Peckiene, A., Komarovska, A., \& Ustinovicius, L. (2013). Overview of risk allocation between construction parties. Procedia Engineering, 57, 889-894. http://doi.org/10.1016/j.proeng.2013.04.113

Said, I., Ayub, A. R., Abdul Razak, A. \& Tee, K. K. (2005). Factors Affecting Construction Organization Quality Management System Malaysian Construction Industry. Retrieved at http://eprints.usm.my/16080/1/lias_Said_2.pdf

Sambasivan, M., \& Soon, Y. W. (2007). Causes and effects of delays in Malaysian construction industry. International Journal of Project Management, 25(5), 517-526. http://doi.org/10.1016/j.jproman.2006.11.007

Sumner, M., \& Slattery, D. (2010). The Impact of Leadership Effectiveness and Team Processes on Team Performance in Construction. International Journal of Construction Education and Research, 6(3), 179-201. http://doi.org/10.1080/15578771.2010.507720

Thalmann, S. (2008). Adaptation Criteria for Preparing Learning Material for Adaptive Usage : Structured Content Analysis of Existing Systems . 12 Content Preparation for Adaptive Systems, (2008), 411-418.

Wan Yusoff Wan Mahmood, Abdul Hakim Mohammed, Mohd. Saidin Misnan, Zakaria Mohd. Yusof, A. B. (2006). Development of Quality Culture in the Construction Industry. Icci 2006, 1-11. 